\title{
Kebutuhan Perancangan Sistem Screening Balita Sakit Berdasarkan Klasifikasi dan Penatalasanaan MTBS
}

\author{
Ida Nurmawati ${ }^{1}$, Feby Erawantini ${ }^{1}$ \\ Jurusan Kesehatan, Politeknik Negeri Jember, Indonesia ${ }^{l}$ \\ e-mail :ida@polije.ac.id
}

\begin{abstract}
The under-five mortality rate (AKBA) in Indonesia in 2015 was 26.29 per 1000 live births. SDG's target of under-five mortality can decrease by 25 per 1000 births by 2030. One of the efforts to reduce under-five mortality is by detecting as early as possible the cause of under-five mortality. The purpose of this study is to identify the needs of designing a system based on Android toddler illness screening. This research is a qualitative research to dig deeper information about system design needs. Data collection is done by brainstorming and documentation. Brainstorming was carried out by involving 2 midwives and 2 nurses as MTBS users at the Puskesmas. Documentation was carried out to obtain information about the 2015 revised MTBS chart. The results of the study found that health workers need applications that are able to detect sick toddlers automatically, health cadres can be empowered in detecting sick toddlers by using sick toddler screening systems, sick toddlers screening systems can help organize MTBS -M. Provide training for health cadres in detecting sick toddlers using the MTBS chart.
\end{abstract}

Keywords: design requirements, screening, toddler

\section{Pendahuluan}

Angka kematian balita (AKBA) di Indonesia tahun 2015 sebesar 26,29 per 1000 kelahiran hidup (Kemenkes,2016). Target SDG's angka kematian balita dapat menurun sebesar 25 per 1000 kelahiran pada tahun 2030. Penyebab kematian anak usia dibawah 5 tahun antara lain infeksi saluran pernapasan akut (ISPA), demam, dan diare (SDKI, 2012).

Angka kematian balita dapat menurun jika penyebab kematian balita dapat dideteksi sedini mungkin sehingga tidak menyebabkan kematian. Terdapat tools manajemen pelayanan kesehatan tingkat pertama yang dapat digunakan untuk mendeteksi balita sakit sejak dini dan memberikan tindakan kesehatan agar dapat mencegah terjadinya kematian balita yaitu Manajemen Terpadu Balita Sakit (MTBS).

MTBS pertama kali disosialisasikan oleh WHO (World Health Organization) di Indonesia tahun 1996 dan tahun 2003 MTBS direkomendasikan oleh Kementerian Kesehatan untuk diimplementasikan di seluruh pelayanan kesehatan dasar (puskesmas) (Titaley, dkk, 2014).

MTBS merupakan suatu pendekatan terpadu atau terintegrasi dalam penatalaksanaan balita sakit dengan fokus kepada kesehatan anak usia 0-59 bulan atau kurang dari 5 tahun secara menyeluruh.
MTBS dilaksanakan pada fasilitas pelayanan kesehatan tingkat pertama atau puskesmas (Kemenkes, 2014). MTBS merupakan tools manajemen yang bertujuan untuk menurunkan kesakitan dan kematian melalui peningkatan kualitas pelayanan kesehatan khususnya dalam penatalaksanaan balita sakit.

Bagan MTBS terdiri dari menilai bayi umur kurang dari 2 bulan dan anak umur 2-59 bulan, menentukan klasifikasi, menentukan tindakan/pengobatan, konseling, pelayanan tindak lanjut (Kemenkes, 2015). Pelaksanaan MTBS tidak terlaksana dengan baik salah satunya adalah karena bagan MTBS yang terlalu panjang dan petugas kesehatan tidak punya banyak waktu untuk mengisi formulir MTBS (Susilaningrum, 2012).

Sebelumnya sudah dilakukan penelitian tentang pembuatan sistem pakar diagnosis penyakit pada anak bawah lima tahun yang mengambil konsep klasifikasi penyakit pada bagan MTBS. Sistem pakar yang dibangun adalah untuk memudahkan dalam mendiagnosis penyakit pada balita (Yanto, dkk, 2017).

Jika konsep seluruh bagan MTBS dapat diadopsi sepenuhnya kedalam bentuk komputerisasi, maka dapat mempermudah petugas dalam implementasi MTBS di pelayanan kesehatan tingkat pertama 
sehingga penemuan kasus dan tindakan kesehatan terpadu bagi balita sakit dapat terlaksana dengan baik.

Berdasarkan uraian tersebut peneliti tertarik untuk mengadopsi konsep MTBS mulai klasifikasi penyakit sampai pemberian solusi atau tindakan kesehatan bagi balita sakit kedalam suatu rancangan sistem berbasis android yang mudah digunakan oleh petugas kesehatan. Sebelum melakukan perancangan sistem screening balita sakit, terlebih dahulu peneliti melakukan identifikasi kebutuhan pengguna dalam perancangan sistem.

\section{Metode}

Penelitian ini merupakan penelitian kualitatif yang bertujuan untuk menggali lebih dalam informasi tentang kebutuhan pengguna dalam perancangan sistem informasi screening balita sakit.

\subsection{Metode Pengumpulan Data}

Jenis data dalam penelitian ini adalah data primer yaitu informasi tentang kebutuhan perancangan sistem dan data sekunder yaitu bagan MTBS revisi 2015. Data primer dikumpulkan dengan cara brainstorming untuk berdiskusi tentang kebutuhan pengguna terhadap sistem screening balita sakit yang dirancang. Data sekunder diperoleh dari dokumen bagan MTBS revisi 2015. Informan merupakan petugas kesehatan yang menggunakan MTBS dalam penatalaksanaan balita sakit di Puskesmas yaitu 2 bidan dan 2 perawat di Puskesmas Jelbuk.

\subsection{Metode Analisis Data}

Analisis data dalam penelitian ini terdiri dari reduksi data, data display, dan verifikasi dan atau kesimpulan. (Sugiyono, 2014) Reduksi data bertujuan untuk memfokuskan data hasil wawancara. Data display bertujuan untuk menyajikan data hasil penelitian agar mudah ditarik kesimpulan. Proses analisis yang terakhir adalah verifikasi dan atau kesimpulan yaitu melakukan verifikasi hasil penelitian dan membuat kesimpulan tentang kebutuhan pengguna terhadap sistem yang dibuat.

\section{Hasil dan Pembahasan}

Metode perancangan atau pengembangan sistem menggunakan metode Waterfall terdiri dari 4 langkah yaitu analisis kebutuhan, desain, pengodean, dan pengujian (Rosa,et.al 2013). Oleh karena itu langkah awal sebelum mendesain sistem screening balita sakit adalah dengan melakukan analisis kebutuhan pada pengguna MTBS di pelayanan kesehatan tingkat pertama. Analisis kebutuhan secara keseluran bertujuan untuk mengetahui alur kerja bagan MTBS revisi 2015 dan untuk mengetahui sistem screening balita sakit yang diinginkan user.

\section{“ kami telah menggunakan aplikasi untuk smartphone untuk memantau ibu dan anak namanya FAI kepanjangannya adalah Fokus Anak dan Ibu. Aplikasi tersebut digunakan untuk memantau kondisi Ibu dan Anak di lapangan yang digunakan oleh bidan Puskesmas. Bidan dapat melakukan pencatatan dan pelaporan ke Puskesmas secara langsung melalui aplikasi FAI.",}

Perancangan sistem screening balita sakit ini merupakan sistem informasi berbasis android kedua yang telah dilakukan di Kabupaten Jember. Untuk menekan angka kematian ibu dan bayi yang tinggi di Kabupaten Jember dikembangkan aplikasi FAI (Fokus Anak dan Ibu) pada tahun 2017 (Warta Unej, 2018).

Aplikasi FAI mempermudah bidan untuk melakukan pencatatan dan pelaporan kondisi ibu dan anak. Hal ini sesuai dengan hasil brainstorming dengan bidan dan nerawat di Puskesmas Ielhık.

$$
\begin{aligned}
& \text { "untuk menggunakan aplikasi } \\
& \text { smartphone seperti FAI kami bisa dan } \\
& \text { bersedia asalkan aplikasi tersebut } \\
& \text { memang mampu membantu mempercepat } \\
& \text { pelayanan kepada pasien." }
\end{aligned}
$$

Hal tersebut menunjukkan bahwa penggunaan aplikasi android tidak asing lagi bagi petugas kesehatan di Kabupaten Jember. Bidan dan perawat menyatakan bahwa penggunaan aplikasi android tidak menjadi kendala bagi petugas kesehatan di Kabupaten Jember selama aplikasi yang akan dibuat dapat membantu petugas dalam mempercepat pelayanan kepada masyarakat. 
MTBS merupakan suatu pendekatan yang terintegrasi dalam penatatalaksanaan balita sakit dengan fokus kepada kesehatan anak berusia 0-59 bulan secara menyeluruh di unit pelayanan kesehatan dasar (Kemenkes, 2014).

MTBS bertujuan untuk
meningkatkan pengetahuan dan keterampilan tenaga kesehatan dalam menangani balita sakit, meningkatkan sistem pelayanan kesehatan dan meningkatkan pengetahuan dan keterampilan ibu dan pengasuh anak dalam perawatan anak serta pencarian pertolongan kesehatan. MTBS dalam mendeteksi balita sakit sampai tindak lanjut memiliki 5 langkah yaitu menilai kondisi balita, menentukan klasifikasi, menentukan tindakan/pengobatan, memberikan konseling bagi ibu, dan memberikan pelayanan tindak lanjut (Kemenkes, 2011).

Penatalaksanaan balita sakit agar memperoleh hasil yang tepat dan akurat harus mengikuti setiap langkah dalam bagan MTBS. Standar pelayanan bagi balita sakit di tingkat pelayanan kesehatan dasar seluruhnya telah termuat pada bagan MTBS yang dapat digunakan secara langsung utamanya oleh tenaga perawat dan bidan (Kemenkes, 2011). Hal ini sesuai dengan hasil brainstorming sebagai berikut :

\section{“ Harusnya semua langkah dalam MTBS dilaksanakan seluruhnya karena memang semua langkahnya terintegrasi mulai dari penilaian kondisi balita sampai pemberian konseling kepada ibu."}

Bagan MTBS yang panjang tersebut menyebabkan tenaga kesehatan khususnya bidan dan perawat tidak dapat menerapkannya secara optimal. Perancangan bagan MTBS menjadi sebuah sistem berbasis android diharapkan mampu membantu petugas kesehatan khususnya bidan dan perawat dalam deteksi dini balita sakit secara cepat, tepat dan akurat.

Berdasarkan hasil brainstorming diketahui bahwa jika bagan MTBS dibuat aplikasi berbasis android maka bidan dan perawat menginginkan aplikasi yang dapat dengan mudah, cepat, dan tepat dalam mendeteksi balita sakit.

\begin{abstract}
" terkadang sulit untuk menggunakan bagan MTBS secara keseluruhan karena jumlah pasien yang banyak setiap harinya. Jika MTBS akan dibuat aplikasi smartphone maka harus mampu deteksi penyakit balita dengan otomatis sehingga pelayanan dapat berjalan cepat."
\end{abstract}

Tujuan perancangan sistem screening balita sakit yang diadopsi dari bagan MTBS dalam penelitian ini selain untuk memudahkan petugas kesehatan, diharapkan juga aplikasi MTBS yang dirancang nantinya dapat dimanfaatkan oleh masyarakat umum. Perawat dan bidan di Puskesmas Jelbuk menjelaskan bahwa MTBS merupakan tools yang hanya diperuntukkan bagi tenaga kesehatan khususnya perawat dan bidan. Perlu pelatihan khusus untuk menggunakan bagan MTBS tersebut.

"MTBS tidak bisa digunakan masyarakat umum karena ada beberapa langkah yang perlu keterampilan khusus dan pengetahuan yang dimiliki oleh petugas kesehatan "

"Mungkin kader kesehatan bisa dilatih untuk menggunakan MTBS versi smartphonenya, hanya untuk membantu petugas kesehatan dalam mendeteksi balita sakit sehingga cepat tertangani. Jadi kader tidak melakukan pengobatan, kader hanya membantu deteksi penyakit, ketika posyandu itu bisa dilakukan kader."

Hasil brainstorming tersebut menunjukkan bahwa bagan MTBS dapat digunakan masyarakat umum dalam hal ini kader kesehatan yang telah diberikan pelatihan guna membantu Puskesmas dalam melakukan deteksi dini balita sakit dan bukan untuk memberikan pengobatan atau tindakan kesehatan lainnya. Namun yang perlu diperhatikan adalah ketersediaan alat kesehatan sebagai sarana pendeteksi balita sakit.

"kalau mau melibatkan kader ya berarti harus menyiapkan sarpras yang dibutuhkan seperti alat yang dibutuhkan untuk melakukan pemeriksaan balita di posyandu." 
"akan sangat membantu jika memang bisa terlaksana karena kader kesehatan merupakan perpanjangan tangan tenaga kesehatan dan lebih dekat dengan masyarakat."

Pendeteksian balita sakit dengan melibatkan kader kesehatan merupakan langkah yang baik karena kader kesehatan merupakan orang yang berada di lingkungan balita yang secara langsung mengetahui kondisi balita. Langkah tersebut dapat membantu mempercepat penemuan balita sakit sehingga balita sakit mendapatkan pertolongan lebih dini.

Pemerintah melalui Peraturan Menteri Kesehatan RI No 70 tahun 2013 telah mengatur penyelenggaraan MTBS berbasis masyarakat. Manajemen Terpadu Balita Sakit Berbasis Masyarakat (MTBS-M) adalah pendekatan pelayanan kesehatan bayi dan anak balita terintegrasi dengan melibatkan masyarakat sesuai standar MTBS. Penyelenggaraan MTBS-M bertujuan untuk meningkatkan akses pelayanan Balita sakit di tingkat masyarakat pada daerah yang sulit akses terhadap pelayanan kesehatan. Pelayanan MTBS-M dilakukan oleh kader setempat yang telah mendapatkan pelatihan sebagai pelaksana dibawah pengawasan tenaga kesehatan dari Puskesmas pelaksana MTBS setempat (Kemenkes, 2013).

\section{Simpulan dan Saran}

\subsection{Simpulan}

a. Petugas kesehatan membutuhkan aplikasi yang mampu mendeteksi balita sakit secara otomatis.

b. Dapat memberdayakan kader kesehatan dalam mendeteksi balita sakit dengan menggunakan sistem screening balita sakit berbasis android.

c. Sistem screening balita sakit dapat membantu penyelenggaraan MTBS-M.

\subsection{Saran}

a. Memberikan pelatihan kepada kader kesehatan untuk melakukan deteksi balita sakit menggunakan aplikasi IMCI berbasis android. b. Memberikan fasilitas pemeriksaan dasar di posyandu yang dapat menunjang deteksi dini balita sakit.

\section{Ucapan Terima Kasih}

Peneliti mengucapkan terimakasih kepada Kementerian Riset, Teknologi dan Pendidikan Tinggi melalui Direktorat Riset dan Pengabdian Masyarakat (DRPM) yang telah membiayai seluruh proses penelitian.

\section{Daftar Pustaka}

Kemenkes. (2016). Profil Kesehatan Indonesia Tahun 2015. Kementerian Kesehatan RI. Jakarta.

Survei Demografi dan Kesehatan Indonesia. (2012). Badan Pusat Statistik, Badan Kependudukan dan Keluarga Berencana Nasional. Kementerian Kesehatan. Jakarta.

Titaley C, Jusril H, Ariawan I, Soeharno N, Setiawan T, Weber M. (2014). Challenges to The Implementation of The Integrated Management of Childhood Illness (IMCI) at Community Health Centres in West Java Province, Indonesia. WHO South-East Asia Journal of Publich Health. Volume 3 (Issue 2):161-170.

Kemenkes. (2014). Peraturan Menteri Kesehatan Republik Indonesia Nomor 25 Tahun 2014 Tentang Upaya Kesehatan Anak. Kementerian Kesehatan RI. Jakarta.

Kemenkes. (2015). Buku Bagan Manajemen Terpadu Balita Sakit (MTBS). Kementerian Kesehatan RI. Jakarta.

Susilaningrum R, Suryawati C, Arso SP. (2012). Pengembangan Model Peningkatan Kinerja Tenaga Keperawatan Dalam Penerapan Manajemen Terpadu Balita Sakit (MTBS) di Surabaya. Jurnal Ners, Vol. 7 No. 1 71-80.

Yanto BF, Werdiningsih I, Purwanti E. (2017). Aplikasi Sistem Pakar Diagnosa Penyakit Pada Anak Bawah Lima Tahun Menggunakan Metode Forward 
Chaining. Journal of Information System Engineering and Business Intelligence. Vol. 3, No.

Sugiyono. (2014). Metode Penelitian Kuantitatif, Kualitatif dan $R \& D$. Penerbit Alfabeta, Bandung.

Rosa A.S., M. S. (2013). Rekayasa Perangkat Lunak. Penerbit Informatika. Bandung.

Warta Unej. (2018). Universitas Jember Bekerjasama Dengan IDI dan Dinas Kesehatan Jember Ciptakan Aplikasi FAI. Available at: http://humas.unej.ac.id/tekan-angkakematian-ibu-dan-bayi-universitasjember-bekerjasama-dengan-idi-dan- dinas-kesehatan-jember-ciptakanaplikasi-fai/?lang=id. Accessed 17 Juli 2018.

Kemenkes. (2011). Pelatihan Jarak Jauh Manajemen Terpadu Balita Sakit Berbasis Komputer/ICATT (IMCI Computerized Adaptation and Training Tool). Kementerian Kesehatan RI. Jakarta.

Kemenkes. (2013). Peraturan Menteri Kesehatan Republik Indonesia Nomor $70 \quad$ Tahun $2013 \quad$ Tentang Penyelenggaraan Manajemen Terpadu Balita Sakit Berbasis Masyarakat. Kementerian Kesehatan RI. Jakarta. 